\title{
LAS TARJETAS DE VISITANTE POR RAZONES HUMANITARIAS: UNA POLÍTICA MIGRATORIA DE PROTECCIÓN ¿E INTEGRACIÓN?
}

\section{Visiting Cards for Humanitarian Reasons: A Migratory Policy of Protection ANd Integration?}

\author{
Eduardo Torre Cantalapiedra* \\ doi: https://doi.org/10.31644/ED.V8.N2.2021.A07
}

Resumen: El objetivo de este trabajo es analizar las tarjetas de visitante por razones humanitarias (TVRH) como instrumento de protección e integración de los migrantes extranjeros en México. Asimismo, se examina el carácter polivalente, discrecional y temporal de estas. Con base en datos de registros administrativos, así como en la revisión bibliográfica y documental, se analiza la manera en que los sucesivos gobiernos mexicanos pusieron en práctica las TVRH en el periodo 2014-2020, prestando especial atención a tres casos de entrega discrecional de estas tarjetas.

Palabras clave: tarjetas de visitante por razones humanitarias, TVRH, migración internacional, protección temporal, centroamericanos, haitianos.

Abstract: The objective of this work is to analyze visitor cards for human reasons (TVRH) as an instrument for the protection and integration of foreign migrants in Mexico. Likewise, the multipurpose, discretionary, and temporary nature of these are examined. Based on data from administrative records, as well as a bibliographic and documentary review, the way in which successive Mexican governments implemented the TVRH in the 2014-2020 period is analyzed, paying special attention to three cases of discretionary delivery of these cards.

Keywords: visitor cards for human reasons, TVRH, international migration, temporary humanitarian protection, Central Americans, Haitians.

\footnotetext{
* Dr. en Estudios de Población, catedrático Consejo Nacional de Ciencia y Tecnología en El Colegio de la Frontera Norte, México. ORCiD: https://orcid.org/0000-0002-4074-3752. Correo-e: etorre@colef.mx.

Fecha de recepción: 24/06/2020. Fecha de aceptación: 25/02/2021. Fecha de publicación: 30/07/2021.

(cc) BY-NC-ND
}

EntreDiversidades. Revista de Ciencias Sociales y Humanidades, Vol. 8, Núm. 2 (17), julio-diciembre 2021. Páginas: 145-166 ISSN-e: 2007-7610. https://doi.org/10.31644/ED.V8.N2.2021.A07 


\section{Introducción}

En las últimas décadas, México ha sido un país de tránsito para cientos de miles de migrantes extranjeros, mayormente procedentes del Norte de Centroamérica (NCA) - Honduras, Guatemala y El Salvador-, que se dirigen principalmente a Estados Unidos tras dejar atrás la pobreza y la violencia en sus países de origen. Existe sobrada evidencia de que estos migrantes son víctimas de multitud de abusos y agresiones durante su tránsito irregular por el territorio mexicano, que se derivan de la violencia y corrupción que asola el país (Calva, et al., 2015; Gómez, 2020). Ante estos flujos migratorios, el gobierno mexicano ha respondido con políticas de control enfocadas en su contención, influido/presionado por el gobierno estadounidense.

Si bien la mayoría de quienes se internan en el país de manera irregular han pretendido llegar a Estados Unidos, recientemente se ha observado que una pequeña parte de los migrantes extranjeros, desde que salen de sus países o conforme evolucionan sus travesías migratorias, contemplan a México como destino final y lugar para establecerse (El Colef, et al., 2020; Torre, 2020). En relación con el flujo que busca asentarse en territorio mexicano, la exclusión de los más desfavorecidos ha sido la norma — como sucede en la gran mayoría los países occidentales-, salvo que el migrante logre "navegar" por una vía legal no convencional que le confiera un estatus regular en el país.

En contraposición con las políticas migratorias de control —contención y exclusiónpracticadas por el gobierno mexicano, este país tiene la obligación moral y la responsabilidad legal de proteger a los migrantes extranjeros, así como, en ciertos casos, facilitar la integración de estos. El gobierno mexicano debe salvaguardar e incorporar a la sociedad mexicana a quienes huyen de Estados incapaces de garantizar un mínimo de respeto de sus derechos humanos (DD.HH.) y que desean establecerse en su territorio, para lo cual el país cuenta con un sistema de protección internacional cuya piedra angular es el refugio (Kerwin, 2018). Asimismo, debe garantizar los DD.HH. —incluida la seguridad personal — de los migrantes que transitan por su territorio ante las múltiples agresiones y abusos que padecen en sus travesías. Sin embargo, las carencias de protección existentes en diferentes ámbitos del fenómeno migratorio requieren del desarrollo de más herramientas para proteger a los migrantes.

Desde la puesta en marcha de la Ley de Migración (LM) de 2011, México cuenta con una novedosa política migratoria de protección: el otorgamiento de tarjetas de visitante por razones humanitarias (TVRH). Este instrumento solo ha sido abordado en la literatura de manera parcial para analizar las políticas migratorias mexicanas en diferentes periodos (París, 2018; Calva y Torre, 2020), pero no existen trabajos que se hayan dado a la tarea de examinarlo exprofeso y a profundidad.

El objetivo de este trabajo es analizar las TVRH como instrumento de protección e integración de los migrantes extranjeros en México. Asimismo, se muestra el carácter polivalente, discrecional y temporal de tales tarjetas. Para ello, este trabajo se divide en dos partes. Primero, se examinan la LM de 2011, el Reglamento de la Ley de Migración (RLM) de 2012 y los Lineamientos para Trámites y Procedimientos Migratorios (LTPM) de 2012, para analizar las TVRH como un instrumento cuyo propósito primigenio es proteger de manera temporal a determinadas poblaciones migrantes bajo ciertas circunstancias; y seguidamente examinar el desempeño

EntreDiversidades. Revista de Ciencias Sociales y Humanidades, Vol. 8, Núm. 2 (17), julio-diciembre 2021. Páginas: $145-166$ ISSN-e: 2007-7610. https://doi.org/10.31644/ED.V8.N2.2021.A07 
que estas tarjetas pueden tener como facilitadoras de la integración y como "salvoconductos". Segundo, a partir de diversas fuentes se indaga sobre las distintas maneras en que el gobierno otorgó las TVRH para atender a los flujos migratorios "tradicionales" — flujos de migrantes que viajan solos, con coyote o en pequeños grupos y que tratan de pasar desapercibidos-, así como otros fenómenos recientes como la llegada de migrantes haitianos (2016-2017) y las caravanas de migrantes centroamericanos de 2018 y 2019. En esta sección, con base en los registros administrativos de la Unidad de Política Migratoria, Registro e Identidad de Personas (UPMRIP), el Instituto Nacional de Migración (INM) y la Secretaría de Gobernación (Segob), se estudian las cifras de las TVRH emitidas en el periodo 2014-2020. Además, mediante la revisión documental, se examinan tres casos de entrega discrecional de mayor relevancia en cuanto al otorgamiento de estas tarjetas.

\section{Las tarjetas de visitante por razones humanitarias (TVRH) Política migratoria de protección polivalente, discrecional y temporal}

Una de las clasificaciones más extendidas de las políticas migratorias ${ }^{1}$ reduce las políticas públicas a dos categorías, las de control de flujos y las de integración (Arango, 2005). Sin embargo, es necesario incorporar una tercera, la protección, especialmente en contextos como el mexicano, al que llegan migrantes necesitados de amparo internacional y otros transitan por el país sufriendo incontables abusos y agresiones. A los efectos de este trabajo, se consideran políticas migratorias de protección a aquellas cuyo propósito primordial es la salvaguarda y defensa de los DD.HH. de los migrantes — especialmente en lo referente a la vida y a la integridad física - ante las violaciones de tales derechos que sufren en sus países de origen, tránsito y destino. Entre las políticas migratorias de este tipo en México cabe mencionar la protección internacional, ${ }^{2}$ los Grupos Beta de Protección a Migrantes y las TVRH.

Aunque clasificamos ciertas políticas migratorias como de protección — porque destacan en este aspecto y es el fin para el cual fueron creadas inicialmente-, se debe tener en cuenta que, primero, no se niega que estas tengan al mismo tiempo una faceta de integración y de control. En este sentido, el análisis realizado de las TVRH se centra en las facetas de protección e integración, pero en otros trabajos se ha dado cuenta de su faceta de control. ${ }^{3}$ Segundo, en la práctica la esencia de estas políticas migratorias puede subvertirse hasta llegar a ser suprimida,

\footnotetext{
${ }^{1}$ En este trabajo se emplea el término más amplio política migratoria —y no el más restringido, política inmigratoriapara referirnos a las políticas públicas respecto a la migración en tránsito e inmigración, así como las relativas a los migrantes en tránsito e inmigrantes que forman parte de tales flujos.

${ }^{2}$ Una de las maneras en que las personas pueden acceder a la protección, cuando residen en un Estado incapaz de asegurar los DD.HH. a sus ciudadanos, o que no tiene la voluntad de salvaguardarlos, es cruzar fronteras internacionales e ir a un país que haya asumido obligaciones internacionales para ser sustituto en la proveeduría de tales derechos (Betts, 2013). En el caso de México, la Ley sobre Refugiados, Protección Complementaria y Asilo Político (LRPCAP) de 2011 recoge tres instrumentos de protección internacional: el refugio, la protección complementaria y el asilo político.

${ }^{3}$ Basok (2020) considera la entrega de TVRH como un instrumento del que se sirven las autoridades para controlar y disciplinar a los migrantes.
}

EntreDiversidades. Revista de Ciencias Sociales y Humanidades, Vol. 8, Núm. 2 (17), julio-diciembre 2021. Páginas: $145-166$ ISSN-e: 2007-7610. https://doi.org/10.31644/ED.V8.N2.2021.A07 
habitualmente en favor de desarrollar una faceta con instrumentos de control y contención. Tercero, no se presume que en su puesta en marcha cuiden de manera efectiva a los migrantes, de la misma forma que cuando se habla de políticas migratorias de control tampoco se está dando a entender con ello que estas sean eficaces en el encauzamiento de los flujos migratorios. Por lo tanto, las TVRH, como cualquier otra política pública, deben ser analizadas de manera crítica.

A continuación, se analizan las TVRH como instrumento de protección. Lo primero que cabe destacar es el carácter polivalente de estas tarjetas, pues pueden ser otorgadas a migrantes extranjeros con diferentes características y bajo diferentes circunstancias, ${ }^{4}$ ya que de acuerdo con el art. 52-V de la LM las personas extranjeras podrán permanecer en territorio nacional bajo la condición de estancia Visitante por Razones Humanitarias (VRH) en los siguientes supuestos específicos: a) Ser ofendido, víctima o testigo de algún delito cometido en territorio mexicano; b) Ser niña, nińo, adolescente migrante (NNAM) no acompañado; c) Ser solicitante de asilo político, de reconocimiento de condición de refugiado o de protección complementaria ante las autoridades mexicanas, en tanto no se resuelva su situación migratoria. Además de estos casos pautados, el último párrafo del art. 52-V permite otorgar esta condición de estancia "a los extranjeros que no se ubiquen en los supuestos anteriores, cuando exista una causa humanitaria o de interés público que haga necesaria su internación o regularización en el país" (art. 52-V, párr. 7, LM). El RLM y los LTPM señalan varias de las situaciones que califican como causa humanitaria:

a. Exista riesgo a su salud o vida propias y requiera permanecer en el territorio nacional; b. Tenga en el territorio nacional a un familiar directo bajo custodia del Estado mexicano y sea necesaria su autorización para prestarle asistencia médica, psicológica, o bien, su intervención para reconocimiento o recuperación de cadáver, o c. Requiera asistir a un familiar directo en estado grave de salud que se encuentre en el territorio nacional (art. 137-IV, RLM); [...] la persona [...] que por su situación de vulnerabilidad no pueda ser devuelto a su país de origen, o no pueda continuar su viaje (art. 63-III, RLM).

El último párrafo del art. 52-V confiere al gobierno mexicano un alto grado de discrecionalidad a la hora de entregar estas tarjetas, en tanto que permite interpretaciones abiertas de lo que se entiende por causa humanitaria — $-\mathrm{O}$, en su caso, de interés público—, por lo tanto, cuenta con un gran potencial para proteger a poblaciones vulnerables bajo diferentes circunstancias.

La regularización de la situación migratoria de personas extranjeras mediante el otorgamiento de la condición de estancia de VRH se hará de acuerdo con el art. 52 de la LM, el art. 137 del RLM y lo dispuesto en los LTPM. Una vez autorizada, las autoridades emiten la TVRH por un año. No obstante, "las personas extranjeras que cuenten con la condición de estancia de VRH podrán solicitar las renovaciones que sean necesarias hasta que concluya el proceso o la causa que originó el otorgamiento de la condición de estancia” (art. 153, párr. 1, RLM). Esta temporalidad

${ }^{4}$ Estas tarjetas no solo tienen la finalidad de proteger a los migrantes, también sirven para otorgar documentos a aquellas personas extranjeras "cuya internación se requiera para apoyar en acciones de auxilio o rescate en situaciones de emergencia o desastre en el territorio nacional” (art. 63-II, RLM).

EntreDiversidades. Revista de Ciencias Sociales y Humanidades, Vol. 8, Núm. 2 (17), julio-diciembre 2021. Páginas: 145-166 ISSN-e: 2007-7610. https://doi.org/10.31644/ED.V8.N2.2021.A07 
de las TVRH puede ser adecuada para los propósitos de protección, pero, como se analiza en el siguiente apartado, supone una limitante en cuanto a la integración de los migrantes.

Si bien el otorgamiento de TVRH no es la panacea para cubrir todos los requerimientos de auxilio de los migrantes frente a la situación de irregularidad, sus poseedores tienen la posibilidad de: 1) Residir durante un ańo en territorio nacional sin estar sujetos al sistema de deportación; por lo tanto, protege frente a su devolución forzosa a países de origen en los cuales pueden no estar garantizados sus DD.HH. o las condiciones de vida ser muy precarias. 2) Trabajar en el país e insertarse en el mercado laboral formal; quienes no disponen de documentación se ven obligados a la informalidad, a los empleos más precarios y son más frecuentemente víctimas de abusos y de explotación. En cualquier caso, quienes cuentan con TVRH han encontrado trabas para encontrar empleo, ya que muchos migrantes son rechazados por empleadores que afirman que estas tarjetas no confieren el derecho a un trabajo formal (Achilli y Negro, 2019). 3) Realizar entradas y salidas múltiples del territorio mexicano (art. 153, párr. 2, RLM). 4) Moverse libremente por todo el territorio nacional. 5) En su caso, renovar las TVRH. 6) Recibir una clave única de registro de población (CURP) que permite el acceso a servicios públicos (entre ellos, los de salud y educación).

\section{Política migratoria de integración y de protección del tránsito}

El análisis de los diferentes supuestos por los cuáles se entregan las TVRH y el carácter temporal de las mismas, permite aseverar que la integración en la sociedad mexicana no es el primer propósito de estas. A excepción de las tarjetas que son entregadas a quienes están en proceso de solicitar refugio en México; en este caso, las TVRH son un instrumento que favorece la integración de quienes podrían ser reconocidos como refugiados - a los cuales se otorga la residencia permanente legal de acuerdo a lo establecido en la Ley sobre Refugiados, Protección Complementaria y Asilo Político (LRPCAP) y la LM-, al permitirles trabajar y acceder a determinados servicios públicos mientras se sustancian sus procedimientos migratorios.

No obstante, por más que los fines de las TVRH fueran otros, cualquier persona con este tipo de tarjeta puede tener la intención de asentarse en México —incluidos aquellos que las obtuvieron tras haber comenzado un proceso de solicitud de refugio pero finalmente fueron rechazados por las autoridades mexicanas- Hay que tener en cuenta que estas tarjetas permiten a los migrantes residir y trabajar en situación regular en México al menos durante un año.

El problema es conservar el estatus legal cuando termina la vigencia de las tarjetas. La renovación de la condición de estancia VRH está supeditada a que se pruebe que la situación por la que fue entregada inicialmente se sigue manteniendo. Sin embargo, esta no incorpora una vía legal para lograr la residencia temporal o permanente en México; los poseedores de una TVRH pueden acceder a dichos estatus solo como resultado de procesos legales separados - como quienes obtienen la residencia permanente por serles reconocida la condición de refugiado- o cambios en sus propias circunstancias — como el matrimonio o ser patrocinado por un empleador formal— (Joseph, Juárez y Martin, 2019).

Desde la perspectiva de los migrantes, sus estrategias y capacidad de agencia, las TVRH significan un año para recurrir a alguna de las vías mencionadas y con ello alcanzar un estatus

EntreDiversidades. Revista de Ciencias Sociales y Humanidades, Vol. 8, Núm. 2 (17), julio-diciembre 2021. Páginas: 145-166 ISSN-e: 2007-7610. https://doi.org/10.31644/ED.V8.N2.2021.A07 
más seguro en términos de asentamiento e integración en el país. Sin embargo, desde el punto de vista del ordenamiento jurídico en México, se puede considerar que conceden un "estatus legal precario" (Oxman-Martinez, et al., 2005; Goldring y Landolt, 2013; Thayer, Stang y Abarca, 2016; Basok y Rojas, 2017). Primero, por el hecho de que no incorpore una vía legal que permita al poseedor quedarse de manera indefinida en el país; por lo tanto, el riesgo de caer o regresar a la irregularidad y de perder el estatus adquirido es mayor. Segundo, porque ofrecen un acceso restringido a los derechos de los residentes permanentes legales o a los de los mismos ciudadanos. Tercero, por la dificultad para hacer valer los derechos que tienen de acuerdo con su condición. Cabe destacar que, al igual que la irregularidad, estos estatus legales precarios son generados por los Estados, quienes activamente crean estas "áreas grises” de incertidumbre (Menjívar, 2006).

Por otra parte, las TVRH pueden ser utilizadas de manera estratégica por los migrantes que desean atravesar México para alcanzar Estados Unidos, pero difícilmente con ellas pueden lograr algún tipo de documento convencional (por ejemplo, visas de turistas). Estas tarjetas permiten a los migrantes: 1) Transitar el territorio sin estar sujetos al sistema de deportación mexicano. 2) Emplear las rutas y medios de transporte más seguros, que están restringidos a quienes se ven orillados a transitar irregularmente. Por lo tanto, son un instrumento de gran eficacia para proteger a los migrantes en sus travesías por el país. De acuerdo con Calleros Alarcón (2013), la exención de visa o el otorgamiento de una visa para transitar son medidas de protección efectivas desde el enfoque de la seguridad humana, pero que conllevan el conflicto diplomático con Estados Unidos. 3) Permite a los migrantes de bajos recursos trabajar para obtener los necesarios para continuar el viaje al norte; entre otros, para pagar a los coyotes que les puedan facilitar el cruce de la militarizada frontera entre México y Estados Unidos.

Varios trabajos han mostrado evidencia anecdótica en cuanto a la solicitud de refugio en México de algunos migrantes con la finalidad de obtener una TVRH que les permita cruzar libremente el territorio mexicano (Torre y Mariscal, 2020). No obstante, esta sería, en todo caso, una estrategia minoritaria entre los migrantes, debido a que requiere invertir mucho tiempo (varias semanas o meses) y recursos. Aunque todos los que reciben este tipo de tarjeta las empleasen para transitar por México — cosa que no sucede_- las cifras de TVRH otorgadas, que no alcanzaron las 100 mil entre 2014 y octubre de 2020, serían reducidas, a comparación con las del tránsito migratorio por México, cuyos flujos incorporan a cientos de miles de migrantes cada año (Rodríguez, 2016; El Colef, et al., 2019).

EntreDiversidades. Revista de Ciencias Sociales y Humanidades, Vol. 8, Núm. 2 (17), julio-diciembre 2021. Páginas: $145-166$ ISSN-e: 2007-7610. https://doi.org/10.31644/ED.V8.N2.2021.A07 


\section{Análisis de la emisión de TVRH \\ Las cifras de los registros administrativos}

Desde el año 2014 el volumen de TVRH otorgadas por el INM creció de manera tan acelerada que en 2019 se entregaron más que en los últimos cinco años (40 966 tarjetas) (ver Gráfica 1). No obstante, la cifra del año 2020 (23 087) supone una importante caída respecto al ańo anterior, pues habría disminuido aproximadamente un 44 por ciento la emisión de estas tarjetas.

Gráfica 1. TVRH otorgadas por el INM, 2014-2020*

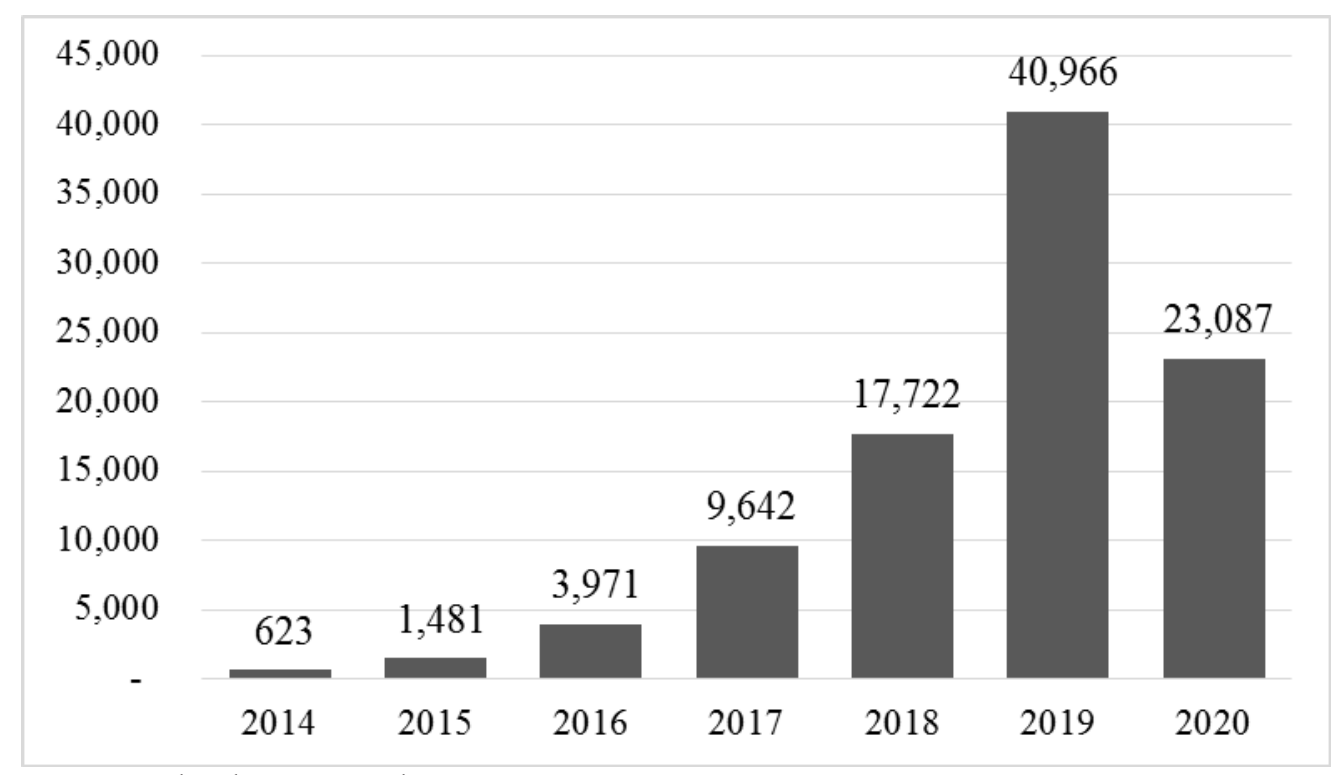

* En 2020, los datos son preliminares.

Fuente: Elaboración propia con base en Gobierno de México, 2020.

Las razones principales del auge exponencial del otorgamiento de TVRH hasta 2019 son dos: 1) el incremento de las solicitudes de estas tarjetas que hacen los migrantes asesorados por las organizaciones de la sociedad civil de acuerdo con los tres casos específicos del art. 52-V de la LM —en especial, las peticiones de estas tarjetas que hacen quienes están solicitando la condición de refugio en México ante la Comisión Mexicana de Ayuda a Refugiados (COMAR)—, y 2) los casos en los que los gobiernos de Enrique Peña Nieto (2012-2018) y de Andrés Manuel López Obrador (2018-actualidad) entregaron de manera discrecional este tipo de documentos a ciertos grupos de personas extranjeras mediante políticas ad hoc (programas especiales). En 2020, la caída se explica en gran medida por la ausencia de entrega discrecional de TVRH y la disminución de los flujos migratorios que llegan a México para asentarse (por ejemplo, mediante la solicitud de refugio); entre otros factores, debido a la emergencia sanitaria de la covid-19. Así, mientras que en 2019 las solicitudes de refugio fueron 70 302, para 2020 cayeron a 36456 (cifra hasta noviembre de 2020) (Ramírez, 2019; 2020a).

EntreDiversidades. Revista de Ciencias Sociales y Humanidades, Vol. 8, Núm. 2 (17), julio-diciembre 2021. Páginas: 145-166 ISSN-e: 2007-7610. https://doi.org/10.31644/ED.V8.N2.2021.A07 
Para una mayor compresión de lo que está sucediendo, resulta oportuno analizar las cifras en función de los orígenes nacionales. En el periodo 2014-2019, los tres países del Norte de Centroamérica (NCA), que son los que tienen mayor tradición migratoria hacia Estados Unidos, coparon el grueso de tarjetas otorgadas (ver Gráfica 2). Estos mismos países destacan en lo que se refiere al volumen de solicitudes de refugio en México (véase al respecto Bermúdez, 2020). Cabe destacar que Honduras por sí solo supone alrededor de la mitad de las tarjetas otorgadas por el INM, alcanzando en el año 2019 el 51.5 por ciento del total, con 21092 tarjetas.

\section{Gráfica 2. Distribución porcentual de TVRH otorgadas por el INM, según país de origen, 2014-2020*}

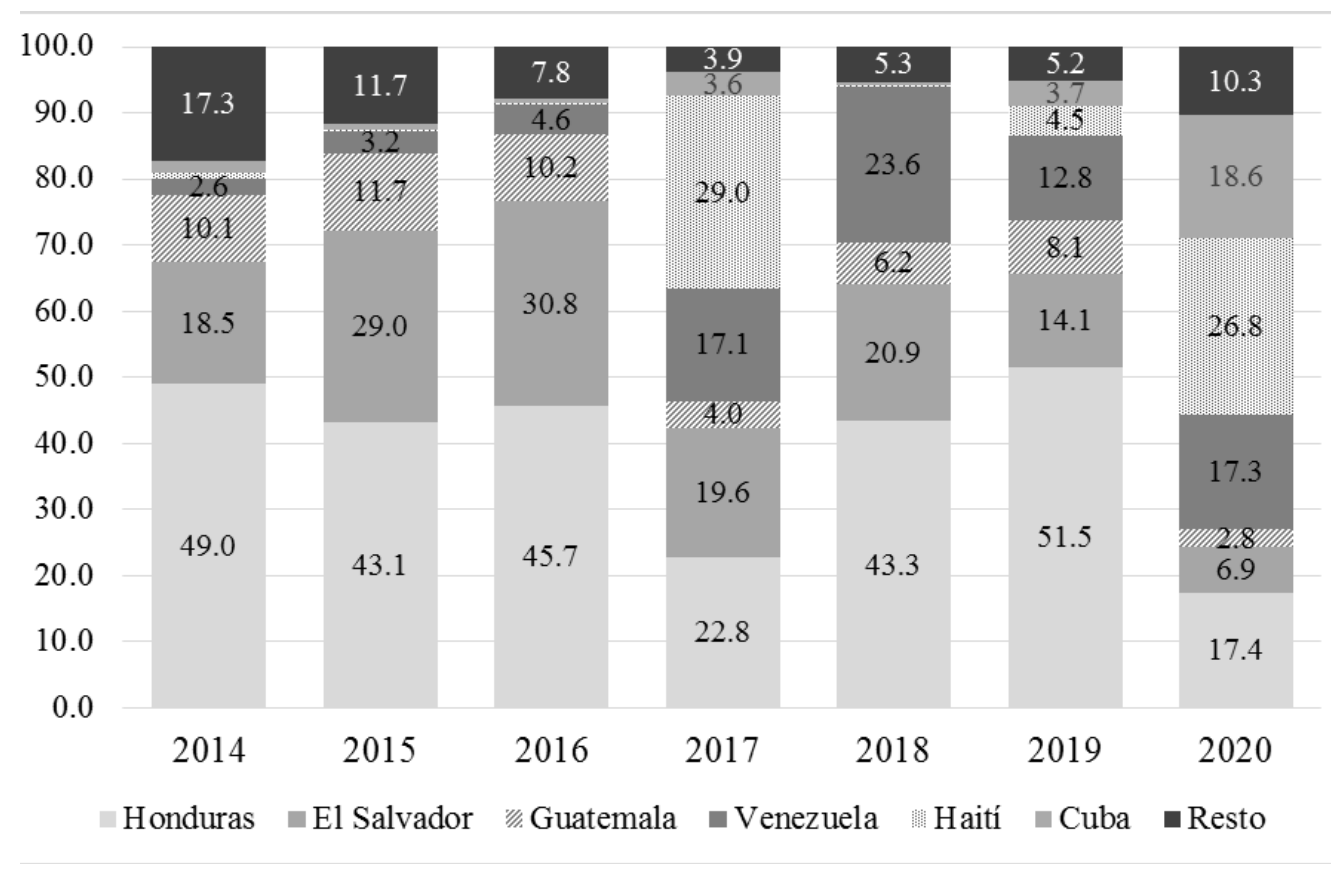

* En 2020, los datos son preliminares e incluyen las tarjetas emitidas hasta octubre.

Fuente: Elaboración propia con base en Gobierno de México, 2020.

Asimismo, se aprecia el auge de las TVRH entregadas a migrantes venezolanos que llegan a México huyendo de la situación política y de vulneración de DD.HH. generalizada que se vive en aquel país en los últimos años. La respuesta que el gobierno mexicano ha dado a los solicitantes venezolanos ha sido la de reconocer como refugiados prácticamente a la totalidad de los solicitantes en seguimiento a la definición de refugiado de la Declaración de Cartagena de 1984 (Observatorio de Protección Internacional, 2019; CEAR, 2018). Así, en 2018 alcanzaron el 23.6 por ciento de las TVRH otorgadas.

Además, la Gráfica 2 permite apreciar que los años 2017 y 2020 tienen una distribución por nacionalidades diferente a la que se observa el resto de años, donde predomina el otorgamiento

EntreDiversidades. Revista de Ciencias Sociales y Humanidades, Vol. 8, Núm. 2 (17), julio-diciembre 2021. Páginas: 145-166 ISSN-e: 2007-7610. https://doi.org/10.31644/ED.V8.N2.2021.A07 
a los tres países del NCA. En 2017, el gobierno de México dio repuesta a la situación que enfrentaban cientos de haitianos en territorio mexicano. Este hecho refiere a otra realidad de cómo han sido empleadas en México las TVRH; bajo circunstancias especiales se han entregado de manera ad hoc a poblaciones vulnerables en su territorio.

En 2020, se puede observar que la participación relativa de los migrantes procedentes de países como Haití y Cuba en el otorgamiento de TVRH se incrementa sustancialmente (26.8\% y 18.6\%, respectivamente), ocupando las dos primeras posiciones. Este auge se produce a raíz de la suspensión en abril de 2019 de la entrega de oficios de salida — documentos que les permitían atravesar el territorio mexicano- a los migrantes haitianos y cubanos (Martínez, F, 2019). A partir de entonces, se incrementó el volumen de solicitudes de refugio de los migrantes haitianos y cubanos, posiblemente para obtener TVRH que les permitiera atravesar México sin ser detenidos y en condiciones más seguras. Presumiblemente, los migrantes de ambos países emplearon esta estrategia en mayor medida que los procedentes de países del NCA. Aunque los países del NCA están entre los más destacados en solicitudes de la condición de refugiado en 2020 - Honduras (13 404 peticiones), El Salvador (3 629) y Guatemala (2 750) (cifras hasta noviembre de 2020) (Ramírez, 2020b)—, resulta llamativo que en 2020 tengan porcentajes $\tan$ bajos en lo que respecta al otorgamiento de las TVRH - Honduras, 17.4\%; El Salvador, 6.9\%; Guatemala, 2.8\%—, por lo que es necesario seguir investigando al respecto, pues podría estar produciéndose una situación discriminatoria en la que se ponga mayores trabas para que los migrantes centroamericanos solicitantes de la condición de refugiado puedan acceder a estas tarjetas.

Gráfica 3. TVRH otorgadas por el INM, según países seleccionados, ene. 2016 a oct. 2020

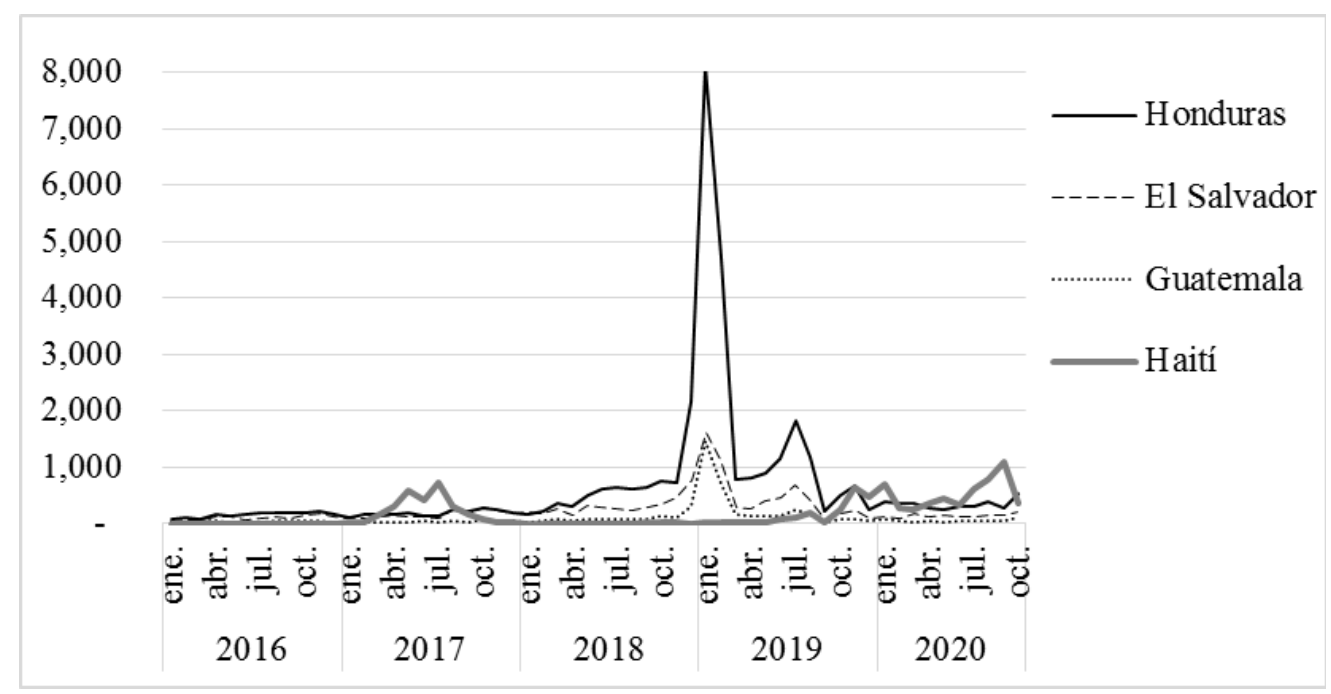

* Los datos de 2020 son preliminares.

Fuente: Elaboración propia con base en Gobierno de México, 2020.

EntreDiversidades. Revista de Ciencias Sociales y Humanidades, Vol. 8, Núm. 2 (17), julio-diciembre 2021. Páginas: 145-166 ISSN-e: 2007-7610. https://doi.org/10.31644/ED.V8.N2.2021.A07 
Cuando la representación del volumen de TVRH entregadas por el INM se realiza mes a mes para países seleccionados, se pueden observar dos rupturas en las tendencias que denotan precisamente momentos en los cuales se atendieron circunstancias particulares mediante estas tarjetas (ver Gráfica 3). La primera, son las 2652 tarjetas otorgadas a los migrantes haitianos entre marzo y septiembre de 2017 — la inmensa mayoría en Baja California_. La segunda, la entrega de casi 21 mil tarjetas a hondureños, salvadoreños y guatemaltecos, principalmente en atención al fenómeno de las caravanas de migrantes centroamericanas entre noviembre de 2018 y febrero de 2019. En el siguiente apartado se analizan ambas rupturas considerando tres casos particulares, pues la segunda de las rupturas engloba dos casos de otorgamiento de TVRH cualitativamente diferentes.

\section{Tres casos de entrega discrecional}

\section{Migrantes haitianos, 2016-2017}

En 2016, a pesar de que no fue un fenómeno de relevancia por su magnitud cuantitativa, los medios de comunicación se hicieron eco de diferentes contingentes de migrantes haitianos que atravesaban México para alcanzar Estados Unidos y solicitar protección internacional. En su mayoría, procedían de Brasil, donde encontraron trabajo y cobijo por unos ańos hasta el empeoramiento de las condiciones económicas en aquel país. Después de atravesar numerosos países, llegaron a ciudades del norte de México, especialmente a Tijuana y Mexicali (Yee, 2017; París, 2018).

La entrada a Estados Unidos fue más difícil de lo esperado, los migrantes haitianos en Tijuana fueron los primeros en experimentar la política de bloqueo y metering de solicitantes de asilo u otras formas de protección internacional. Estas medidas emprendidas por el gobierno de Barack Obama consistían, respectivamente, en impedir el acceso directo a solicitar asilo en Estados Unidos y regular/limitar el número de migrantes cuyas solicitudes eran procesadas diariamente; compeliendo con ello a miles de peticionarios haitianos a esperar durante semanas o incluso meses en México para iniciar sus solicitudes de protección ante autoridades estadounidenses. Por tanto, tuvieron que quedarse en ciudades fronterizas de México cuyas tasas de delincuencia y violencia se cuentan entre las más elevadas de este país, lo que implicó que frecuentemente fueran víctimas de agresiones, robos y asaltos, secuestros e incluso asesinatos (Robert Strauss Center, et al., 2018; Heyman y Slack, 2018).

Muchos de los haitianos decidieron reformular sus proyectos migratorios y permanecer en México, al menos durante un tiempo, a medida que no prosperaban sus solicitudes de protección en Estados Unidos y eran deportados a Haití debido a los cambios en sus políticas, en especial tras la llegada del Donald Trump a la presidencia (Yee, 2017). Su estancia en las ciudades fronterizas se dilató tanto, que se discute si se trataba de un tránsito prolongado o del establecimiento de un nuevo destino para la migración haitiana (Méroné y Castillo, 2018). Se estima que fueron alrededor de 3500 los que se quedaron en la ciudad de Tijuana en 2017.

La manera en que las autoridades migratorias del gobierno de Enrique Peña Nieto trataron el éxodo haitiano fue mayormente improvisada según las necesidades del momento. Al internarse en el país, el INM no les aplicó la política habitual de detener y deportar, sino que, por motivos

EntreDiversidades. Revista de Ciencias Sociales y Humanidades, Vol. 8, Núm. 2 (17), julio-diciembre 2021. Páginas: 145-166 ISSN-e: 2007-7610. https://doi.org/10.31644/ED.V8.N2.2021.A07 
mayormente pragmáticos, les fueron entregados "oficios de salida” en las estaciones migratorias, documentos que establecían un plazo de 20 días naturales para proceder a regularizar su situación en México o salir del país (Castañeda, Coria y Pérez, 2018). La gran mayoría empleó esta documentación como "salvoconducto" para transitar de un modo relativamente rápido y seguro hasta Tijuana y Mexicali (París, 2018).

Después de quedarse por un largo tiempo en México, la delegación federal del INM de Baja California les brindó información sobre cómo regularizar su estatus legal en el país a través de la condición de estancia VRH; a la que cientos de los migrantes haitianos se acogieron en Tijuana, aunque el plazo marcado en los oficios de salida hubiese expirado (Castańeda, Coria y Pérez, 2018). En el año 2017, en Baja California se emitieron 2723 TVRH a migrantes haitianos, las cuales les permitieron residir y trabajar en el país, al menos durante un año (Gobierno de México, 2020).

Esta es la primera ocasión en que se utilizaron las TVRH de acuerdo con el último párrafo del art 52-V de la LM para resolver la situación de una población que se encontraba imposibilitada de continuar su viaje a Estados Unidos. El Consejo Ciudadano del INM abogó por este tipo de solución señalando que esta disposición legal es "una cláusula abierta para hacer frente precisamente a situaciones no previsibles pero que igualmente constituyen una causa humanitaria o de interés público como es el caso de los haitianos y africanos en México” (CCINM, 2017).

\section{Caravanas de migrantes a finales de 2018}

Entre octubre y noviembre llegaron a México un conjunto de caravanas de migrantes - grupos de varios miles procedentes principalmente de Honduras y en menor medida de El Salvador y Guatemala- que partieron del territorio hondureño y salvadoreño. Al llegar a la frontera entre Guatemala-México la mayoría optó por cruzar el río Suchiate y seguir su camino a Estados Unidos en situación irregular (Pradilla, 2019a). Sin embargo, no todos los participantes en las caravanas tenían la intención de alcanzar el territorio estadounidense, algunos buscaban establecerse en suelo mexicano, mientras otros marchaban sin haber fijado un destino.

Ante la llegada de la primera caravana, las autoridades mexicanas señalaron que solo se permitiría el ingreso a aquellas personas que portasen documentos de viaje y visa, o solicitaran el reconocimiento de la condición de refugiado, y que se detendría y deportaría a todo aquel que se internara en el país de manera irregular (SRE y Segob, 2018). Sin embargo, en los hechos, fueron indulgentes con el tránsito irregular de los participantes de la caravana, que en su mayoría llegaron a Tijuana por la ruta del Pacífico buscando alcanzar Estados Unidos (El Colef, 2019). Las razones de esta permisividad no son del todo claras. ¿Fue el escrutinio internacional de tan mediáticas caravanas?, ¿razones humanitarias ante la precaria situación de los participantes en las mismas?, ¿la indecisión o falta de operatividad ante un fenómeno migratorio sin precedentes? o ¿el momento de transición entre gobiernos que se vivía?

Aunque muchos participantes en la caravana tenían la vana esperanza de que una vez en la frontera con Estados Unidos se les permitiese entrar en aquel país de un modo excepcional, la realidad que encontraron fue un muro inexpugnable en dicha región fronteriza (Baja California), cuya única opción viable de cruce era la solicitud de asilo; algo que a priori no resultaba

EntreDiversidades. Revista de Ciencias Sociales y Humanidades, Vol. 8, Núm. 2 (17), julio-diciembre 2021. Páginas: 145-166 ISSN-e: 2007-7610. https://doi.org/10.31644/ED.V8.N2.2021.A07 
conveniente para la mayoría de ellos, al no reunir los requisitos establecidos en la legislación estadounidense. Los que decidieron seguir este cauce legal y aceptar los señalamientos de las autoridades estadounidenses, tuvieron que enfrentar el metering, de la misma forma que lo habían hecho con anterioridad los migrantes haitianos, mexicanos y de otros países. Los solicitantes a través de los puertos de entrada de Tijuana tuvieron que anotarse en una lista en la que ya estaban apuntadas 2800 personas, con un tiempo estimado de espera superior a las cinco semanas (Aristegui Noticias, 2018). Además, tras el arribo de estas caravanas de migrantes a la ciudad, los tiempos dilataron a 12 semanas, con una lista de espera de aproximadamente 5000 personas (Robert Strauss Center, et al., 2018).

Para atender a las caravanas en la ciudad de Tijuana, las autoridades mexicanas habilitaron un "albergue provisional” en la Unidad Deportiva Benito Juárez, el cual fue posteriormente clausurado por motivos de hacinamiento y salubridad. Así, fueron reubicados en El Barretal, un espacio dedicado anteriormente a eventos y conciertos, donde las condiciones fueron algo mejores, pero seguían siendo altamente precarias. No obstante, varios de los migrantes prefirieron autoorganizarse en el albergue Contra Viento y Marea (El Colef, 2019). Las autoridades volvieron a utilizar el mismo mecanismo que se empleó anteriormente con los migrantes haitianos en dicha ciudad, esto es, se les otorgó las TVRH. Los trámites fueron mucho más rápidos de lo que es habitual para la entrega de este tipo de documentos. Mientras que de enero a octubre de 2018 se entregaron en Baja California 165 tarjetas, la cifra de noviembre (105) era considerablemente mayor al promedio de meses anteriores, pero fue el mes siguiente el que despuntó con el otorgamiento generalizado de TVRH a los participantes de las caravanas con 1858 tarjetas —en su mayoría migrantes de países del NCA — (Gobierno de México, 2020).

Estas tarjetas fueron un recurso estratégico muy importante, tanto para quienes decidieron establecerse en México como para quienes no abandonaron sus planes de cruzar a Estados Unidos (Torre y Mariscal, 2020). A los primeros, les permitía insertarse en el mercado laboral mexicano en mejores condiciones que sin papeles, evitar la posibilidad de ser deportados e ir a buscar empleo a cualquier lugar de México. Por ejemplo, a Lorena y Víctor las TVRH les facilitó trabajar primero en Tijuana y luego moverse a Reynosa buscando mejores condiciones laborales (experiencia migratoria recuperada en París y Montes, 2020). A los segundos, estas tarjetas les posibilitó marchar libremente — sin ser detenidos ni deportados - hacia otras regiones de la frontera entre México y Estados Unidos para realizar el cruce indocumentado, todo ello utilizando los medios de transporte convencionales. Además, estas tarjetas les permitió trabajar regularmente durante un tiempo en México para sufragar su cruce irregular; inclusive regresar a sus países de origen para volver a intentar más adelante el cruce a Estados Unidos, sin el riesgo de ser detenidos y deportados.

\section{Caravanas de migrantes de inicios de 2019}

Ante la llegada de una nueva caravana en 2019, el gobierno de López Obrador respondió de un modo diametralmente opuesto al predecesor: al llegar a la frontera Guatemala-México entregaron a los migrantes una identificación —un brazalete — bajo la promesa de darles TVRH a todos los integrantes de la caravana que reunieran ciertos requisitos legales básicos (Pradilla, 2019b). Algunos desconfiaron de las autoridades mexicanas o prefirieron no esperar los cinco

EntreDiversidades. Revista de Ciencias Sociales y Humanidades, Vol. 8, Núm. 2 (17), julio-diciembre 2021. Páginas: 145-166 ISSN-e: 2007-7610. https://doi.org/10.31644/ED.V8.N2.2021.A07 
días que dijeron tardarían en darles las tarjetas. ${ }^{5}$ No obstante, las autoridades cumplieron con lo prometido, en enero y febrero entregaron en Chiapas 10473 y 3701 TVRH, respectivamente (Gobierno de México, 2020), en su gran mayoría a migrantes procedentes del NCA. Durante la vigencia del "Programa emergente de emisión de TVRH en la frontera México-Guatemala" hasta su finalización el 28 de enero de 2019, se otorgaron este tipo de documentos de manera generalizada a todos los migrantes que llegaban a la frontera sur.

¿Por qué entregar TVRH a quienes habitualmente se les negaba cualquier clase de visa debido a su estatus económico? El propósito de esta entrega era que los visitantes se quedaran a trabajar en territorio mexicano y no prosiguieran su camino hacia el norte. En febrero de 2019, la Secretaria de Gobernación, Olga Sánchez Cordero, valoró positivamente esta entrega de TVRH, afirmando que solo el diez por ciento llegó a la frontera norte porque México era un lugar atractivo para quedarse (Migration Policy Institute, 2019). Sin poner en duda que algunos de quienes recibieron este documento se quedaran, la cifra señalada por Sánchez Cordero resulta poco probable, pues muchos habían solicitado la visa con la intención de facilitar su paso hasta el norte para después cruzar de manera irregular a Estados Unidos o solicitar asilo en aquel país (Semple, 2019). Existe mucha evidencia de que el territorio estadounidense sigue siendo el destino predilecto de los migrantes procedentes del NCA, entre ellos, los participantes de las caravanas de finales de 2018 (El Colef, et al., 2019; El Colef, 2019).

Para el mes de marzo, la entrega de este tipo de documentos regresaba a cantidades que corresponden al otorgamiento convencional, que está mayormente constreñido a situaciones específicas del artículo 52-V. De hecho, el discurso del gobierno mexicano respecto a las tarjetas también cambió. Según declaraciones de Sánchez Cordero, las TVRH dejaron de ser una política exitosa, pues las mismas estarían promoviendo, según las autoridades mexicanas, la migración irregular.

Las detenciones y deportaciones incrementaron de manera sustancial. Si bien las cifras de detenciones de marzo y abril no fueron las más destacadas del año 2019, quedaba patente que las autoridades mexicanas estaban haciendo un esfuerzo por contener la migración irregular, lo que se comprueba particularmente con las cifras de abril: 21204 detenciones (Calva y Torre, 2020).

La entrega de TVRH, otras acciones favorables a los migrantes y el discurso pro-migrante de la administración de López Obrador posiblemente contribuyeron a que la migración irregular hacia Estados Unidos aumentase. Lo que pasó después es de sobra conocido. En mayo de 2019, el auge de la migración que llegaba hasta la frontera México-Estados Unidos para cruzar irregularmente o solicitar asilo sirvió de base para que el presidente estadounidense amenazase a México con una subida de aranceles, lo cual condujo a una negociación y seguidamente a una declaración conjunta en la que México se comprometía a llevar a cabo medidas efectivas para reducir la cifra de migrantes que llegaban hasta la frontera norte.

\footnotetext{
${ }^{5}$ Entre los migrantes que dudaban estaba Wendy (hondureńa, 31 ańos), quien formó parte de la primera caravana a finales de 2018. Ella fue de la minoría que no cruzó el Suchiate en aquel entonces y se entregó a las autoridades mexicanas; al cabo de cinco días, cuando se dio cuenta que no podría proseguir al norte pidió su deportación (experiencia migratoria recuperada en Martínez, C., 2019).
}

EntreDiversidades. Revista de Ciencias Sociales y Humanidades, Vol. 8, Núm. 2 (17), julio-diciembre 2021. Páginas: $145-166$ ISSN-e: 2007-7610. https://doi.org/10.31644/ED.V8.N2.2021.A07 
Los tres casos analizados permiten observar que en los últimos ańos los gobiernos mexicanos han estado experimentando/empleando esta política migratoria de protección de entrega de TVRH para situaciones dispares en las que se encontraban implicados migrantes en situación de especial vulnerabilidad, quienes se presume las han usado tanto para establecerse en México como para transitar por este país en mejores condiciones que si careciesen de tales documentos.

En el correspondiente a los migrantes haitianos que llegaron a las ciudades de Tijuana y Mexicali, se entregaron documentos a aquellas personas que habían decidido quedarse en México, por lo que esta fue una alternativa humanitaria para apoyarlos. No obstante, la medida también puede ser calificada de otro modo bien distinto, pues las autoridades optaron por esta vía legal para evitar las dificultades políticas y económicas de deportarlos a Haití, al mismo tiempo que servía a fines de control migratorio (Basok, 2020). En cuanto a los centroamericanos participantes en las caravanas de finales de 2018 que llegaron a Tijuana y Mexicali, el INM les entregó TVRH casi desde un primer momento y de manera expedita. Nuevamente se estaba apoyando a aquellos que quisieran quedarse en territorio mexicano, en algunos casos mientras durase su procedimiento de asilo ante las autoridades estadounidenses. En ambas situaciones, las tarjetas fueron entregadas en Baja California a quienes ya habían recorrido todo el país de sur a norte y que estaban en una zona donde el cruce irregular a Estados Unidos es virtualmente imposible.

La entrega de TVRH en enero y febrero de 2019 en la frontera sur, mayormente a migrantes del NCA, fue muy distinta de los casos anteriores. Al entregarse los documentos antes de que hubieran transitado por el país, podían ser usados como salvoconducto para cruzarlo, además de la posibilidad de emplearse en México al menos durante un año. Al igual que con las caravanas de finales de 2018, se trataba mayormente de migrantes centroamericanos procedentes del NCA. De alguna manera, el gobierno de López Obrador estaba facilitando la movilidad de los migrantes en situación de pobreza de Centroamérica hacia el Norte Global, algo que contradice el régimen mundial de gobernanza de las migraciones que a través de políticas restrictivas confinan a gran parte de la población mundial a países donde hay alto desempleo y los salarios son extremadamente bajos.

Tras las presiones de Estados Unidos, especialmente con la amenaza arancelaria de mayo de 2019, resulta difícil pensar que una entrega generalizada de TVRH vuelva a producirse en los próximos años, al menos cuando los migrantes apenas acaban de llegar al territorio mexicano. Así, en enero de 2020, con la llegada de una nueva caravana procedente de Honduras, la Secretaria de Gobernación señaló:

México no es solamente un país de tránsito. No es un país que dé un salvoconducto, es un país que abre sus puertas a las personas que quieran entrar y migrar a nuestro país. De ninguna manera tenemos visas de tránsito o bien salvoconductos (Sánchez Cordero, citada en Pradilla, 2020a).

Además de la discrecionalidad, el análisis de estos casos permite constatar que la temporalidad de las TVRH plantea importantes problemas entre aquellos que quieren asentarse en México y demuestra que se trata de un estatus legal precario, tanto por la posibilidad de caer en la irregularidad como por los pocos derechos que concede y las dificultades de hacerlos valer.

EntreDiversidades. Revista de Ciencias Sociales y Humanidades, Vol. 8, Núm. 2 (17), julio-diciembre 2021. Páginas: 145-166 ISSN-e: 2007-7610. https://doi.org/10.31644/ED.V8.N2.2021.A07 
En Mexicali (Baja California) algunos haitianos que llegaron entre 2016 y 2017 han tenido problemas para renovar sus visas y permanecer en situación regular en territorio mexicano, por no contar con un trabajo en una empresa que esté registrada ante el INM (UniMexicali, 2018). También se puede ilustrar esta problemática en el caso de los participantes en las caravanas. Jason Martínez (hondureño, 22 años, vendedor ambulante), quien formó parte de la primera caravana que llegó en enero de 2019 a México y recibió una TVRH por parte de las autoridades mexicanas en Chiapas, aprovechó esta tarjeta para instalarse en Monterrey como vendedor ambulante de semillas (experiencia migratoria recuperada por Pradilla, 2020b).

Su problema: se venció la tarjeta y el INM no quiso renovarla. Bajó a Chiapas para realizar el trámite, pero le dijeron que no podría regularizar su situación. Así que se volvió a convertir en ilegal. Después de un año viviendo legalmente en Monterrey terminó encerrado en la estación migratoria Siglo XXI (Pradilla, 2020b).

En estos casos de entrega de documentos bajo programas especiales, al no quedar claro en qué se sustenta el otorgamiento, hace más difícil que se pueda acudir a la vía de la renovación, que requiere probar que las circunstancias o procesos por los que se otorgó la documentación inicialmente se siguen manteniendo (Joseph, Juárez y Martin, 2019). Por ello, es todavía más acuciante que logren transitar con éxito hacia otros estatus legales que podrían considerarse más seguros como la residencia temporal o la residencia permanente — ya sea porque logren la condición de refugiado, consigan un trabajo que sea reconocido por el INM o por cualquier otra vía legalmente establecida-.

\section{Comentarios finales}

Las TVRH son un instrumento que ha servido para proteger a poblaciones migrantes en diversas circunstancias y sus beneficiados se cuentan por decenas de miles en el periodo 2014-2020. La emisión de estas tarjetas se incrementó sustancialmente en aplicación de los casos tasados en la ley — sobre todo, en lo referente a solicitantes de la condición de refugiado procedentes de los tres países del NCA; seguidos de Venezuela, Haití, y Cuba-; y también de acuerdo con programas especiales, como se comprueba a través de los tres casos de entrega ad hoc examinados: la migración haitiana (2016-2017) en Baja California, los participantes de las caravanas de migrantes de finales de 2018 en Baja California y los integrantes de la caravana de migrantes de inicios de 2019 en Chiapas.

La polivalencia y la discrecionalidad hacen de las TVRH una herramienta útil y adaptativa para la protección de poblaciones migrantes en muy diversas circunstancias de su tránsito y asentamiento. Sin embargo, ambas características también implican aspectos negativos. Así, el carácter polivalente de esta política migratoria de protección en contextos como el actual —en el que México está fuertemente presionado por Estados Unidos para contener a los migrantes-, un instrumento que puede servir como "salvoconducto" para atravesar el país, resulta muy problemático. En este sentido, el gobierno mexicano difícilmente volverá a entregar este tipo

EntreDiversidades. Revista de Ciencias Sociales y Humanidades, Vol. 8, Núm. 2 (17), julio-diciembre 2021. Páginas: $145-166$ ISSN-e: 2007-7610. https://doi.org/10.31644/ED.V8.N2.2021.A07 
de tarjetas de manera indiscriminada a migrantes centroamericanos, y de otros países, nada más internarse a su territorio por la frontera sur, como sí hizo en enero de 2019. Lo más probable es que en los próximos años el uso de las TVRH se restrinja a los casos tasados en la legislación, cuando las autoridades estén compelidas a otorgarlas, por lo que es posible que la dificultad para obtenerlas sea mucho mayor. Incluso en un escenario como el de la pandemia de la covid-19, que admite y requiere del uso de este tipo de herramientas, no se ha anunciado ningún programa especial de otorgamiento de TVRH para los migrantes de bajos recursos procedentes de Centroamérica y otros países.

Por su parte, la discrecionalidad que permite ir más allá de los casos tasados y hacer uso de estas tarjetas en diversas situaciones, no solo sirve a propósitos altruistas y solidarios de protección; también hace de las TVRH un instrumento que puede emplearse para generar una imagen positiva de la actuación del gobierno, dar una solución meramente pragmática a una determinada situación, incrementar la vigilancia sobre una cierta población, entre otros intereses políticos.

En cuanto a la temporalidad de las TVRH, aunque su duración limitada armonice con su faceta protectora, no lo hace en el aspecto de la integración, pues la vigencia de un año se torna una cuestión problemática. En este sentido, estas tarjetas conceden un estatus legal precario. Pasado el periodo de un año, la situación migratoria de muchas de estas personas deviene en irregular, por lo tanto, sujetos a mayor explotación laboral y a los procesos de deportación. A pesar de esta limitación, para aquellos que pretenden asentarse o trabajar temporalmente en México, las TVRH les dan un ańo de seguridad jurídica y a partir de esta estancia muchos logran transitar a estatus migratorios relativamente más seguros.

Los resultados de este trabajo sugieren que se deben generar datos que permitan profundizar en mayor medida sobre las causales por las que fueron otorgadas tales tarjetas y cómo fueron empleadas por parte de los migrantes en la práctica. También apunta a la necesidad de responder a diversas interrogantes mediante investigaciones de corte cualitativo - y también mixto-, entre otras: ¿qué obstáculos encuentran los migrantes para que les sean otorgadas estas tarjetas?, ¿cómo han sido los procesos de integración de quienes las poseen?, ¿de qué maneras son empleadas durante el tránsito?, ¿han permitido un mayor acceso a la justicia?

Finalmente, este tipo de tarjetas no deben entenderse como un sustituto de ninguno de los restantes instrumentos de protección de los que dispone México, sino complementario a estos. El éxito del gobierno en la protección efectiva de las personas migrantes extranjeras tiene que ver con el correcto desempeño de cada una de las herramientas de protección actualmente disponibles y el desarrollo de otras nuevas para enfrentar los retos pendientes.

EntreDiversidades. Revista de Ciencias Sociales y Humanidades, Vol. 8, Núm. 2 (17), julio-diciembre 2021. Páginas: 145-166 ISSN-e: 2007-7610. https://doi.org/10.31644/ED.V8.N2.2021.A07 


\section{Bibliografía citada}

Achilli, Luigi y Negro, Virginia (2019). "Work Toward Integration: Labour Inclusion of Migrants in Mexico". Policy Briefs [en línea], Vol. 26, pp. 1-8. Disponible en: http:// hdl.handle.net/1814/65504 (Consultado el 20 de diciembre de 2020).

Arango, Joaquín (2005). "Dificultades y dilemas de la política de inmigración”. Arbor [en línea], 181 (713), pp. 17-25. doi: http://dx.doi.org/10.3989/arbor.2005.i713.439 (Consultado el 23 de junio de 2020).

Aristegui Noticias (2018). "Migrantes tendrán que esperar hasta dos meses para solicitar asilo en EU”. Aristegui Noticias [en línea]. Disponible en: https://aristeguinoticias.com/2811/ mexico/migrantes-tendran-que-esperar-hasta-dos-meses-para-solicitar-asilo-en-eu (Consultado el 23 de junio de 2020).

Basok, Tanya y Rojas Wiesner, Martha L. (2017). "Precarious Legality: Regularizing Central American Migrants in Mexico". Ethnic and Racial Studies, 41 (7), pp. 1274-1293. También disponible en: https://doi.org/10.1080/01419870.2017.1291983

Basok, Tanya (2020). "Documentar a las personas migrantes en México: ¿Protegiendo a los vulnerables o disciplinando a los ingobernables?", en Sandoval García, Carlos (ed.). Puentes, no muros. Contribuciones para una politica progresista en migraciones. Argentina y México: CLACSO y Fundación Rosa Luxemburg. Disponible en: http://biblioteca. clacso.edu.ar/clacso/se/20200327054129/Puentes-no-muros.pdf (Consultado el 23 de diciembre de 2020).

Bermúdez Lobera, Juan (2020). "Análisis sobre los eventos de presentación y devolución de personas migrantes por parte del Instituto Nacional de Migración entre 2011 y 2019". Movilidades. Análisis de la Movilidad Humana [en línea], (4), pp. 8-19. Disponible en: http:/www.politicamigratoria.gob.mx/work/models/PoliticaMigratoria/CEM/ Publicaciones/Revistas/movilidades/4/movno4.pdf (Consultado el 23 de junio de 2020).

Betts, Alexander (2013). Survival Migration: Failed Governance and the Crisis of Displacement. United States of America: Cornell University Press. doi: http://doi.org/10.7591/ cornell/9780801451065.001.0001 (Consultado el 23 de junio de 2020).

Calleros Alarcón, Juan Carlos (2013). "Seguridad pública y seguridad humana en la migración indocumentada en tránsito por México”. Foro internacional [en línea], 53, 2 (212), abriljunio, pp. 317-336. Disponible en: https://forointernacional.colmex.mx/index.php/fi/ article/view/2136/2126 (Consultado el 23 de junio de 2020).

Calva Sánchez, Luis Enrique, et al. (2015). Principales Resultados de la Encuesta Sobre Agresión y Abuso a Migrantes (EAAM) devueltos por las autoridades migratorias, 2012 [en línea]. México: El Colegio de la Frontera Norte. Disponible en: http://www.colef.mx/wpcontent/uploads/2015/03/EAAM 19 marzo.pdf (Consultado el 23 de junio de 2020).

Calva Sánchez, Luis Enrique y Torre Cantalapiedra, Eduardo (2020). "Cambios y continuidades en la política migratoria durante el primer año del gobierno de López Obrador". Norteamérica. Revista Académica del CISAN-UNAM [en línea], 15 (2), pp. 3-27. doi: https://doi. org/10.22201/cisan.24487228e.2020.2.415 (Consultado el 2 de octubre de 2020).

EntreDiversidades. Revista de Ciencias Sociales y Humanidades, Vol. 8, Núm. 2 (17), julio-diciembre 2021. Páginas: 145-166 ISSN-e: 2007-7610. https://doi.org/10.31644/ED.V8.N2.2021.A07 
Castañeda, Alejandra, Elba Coria Márquez y Gabriel Pérez Duperou (2018). "Marco normativo en México y Estados Unidos y situación jurídico-legal de los migrantes haitianos”, en París Pombo, María Dolores (coord.). Migrantes haitianos y centroamericanos en Tijuana, Baja California, 2016-2017. Politicas gubernamentales y acciones de la Sociedad civil. México: Comisión Nacional de los Derechos Humanos México y El Colegio de la Frontera Norte, pp. 71-93. Disponible en: https://www.cndh.org.mx/sites/all/doc/Informes/Especiales/ Informe-Migrantes-2016-2017.pdf (Consultado el 23 de junio de 2020).

Comisión Española de Ayuda al Refugiado (CEAR) (2018). México: Destino forzoso para personas refugiadas [en línea]. Madrid, España: Comisión Española de Ayuda al Refugiado, Agencia Extremeña de Cooperación Internacional. Disponible en: https://www.cear.es/wp-content/ uploads/2018/05/INFORME MEXICO.pdf (Consultado el 23 de junio de 2020).

Consejo Ciudadano del Instituto Nacional de Migración (CCINM) (2017). Grupos de trabajo: repatriaciones/Visas por razones humanitarias. Caso: haitianos y africanos en la frontera norte de México [en línea]. Ciudad de México, México: Consejo Ciudadano del Instituto Nacional de Migración. Disponible en: https:/www.gob.mx/cms/uploads/attachment/file/281220/ Informe Caso Haitianos y Africanos.pdf (Consultado el 23 de junio de 2020).

El Colegio de la Frontera Norte (El Colef) (2019). La caravana de migrantes centroamericanos en Tijuana 2018-2019. (Segunda Etapa) [en línea]. México: El Colegio de la Frontera Norte. Disponible en: https://www.colef.mx/estudiosdeelcolef/la-caravana-de-migrantescentroamericanos-en-tijuana-2018-2019-segunda-etapa/ (Consultado el 23 de junio de 2020).

El Colegio de la Frontera Norte (El Colef), et al. (2019). Encuesta sobre Migración en la Frontera Sur de México, Informe anual de Resultados 2018 [en línea]. México: El Colegio de la Frontera Norte, A.C., Unidad de Política Migratoria, Registro e Identidad de Personas, Consejo Nacional de Población, Secretaría de Relaciones Exteriores, Secretaría del Trabajo y Previsión Social, Consejo Nacional para Prevenir la Discriminación, Secretaría de Bienestar. Disponible en: https://www.colef.mx/emif/datasets/informes/sur/2018/ Emif\%20Sur\%20Informe\%20Anual\%202018.pdf (Consultado el 23 de junio de 2020).

El Colegio de la Frontera Norte (El Colef), et al. (2020). Encuesta sobre migración en la frontera sur de México. Boletin Emif Sur. Reporte semestral julio-diciembre 2019. Flujos de devueltos por las autoridades mexicanas y estadounidenses a Guatemala y Honduras: el tránsito migratorio [en línea]. México: El Colegio de la Frontera Norte, A.C., Unidad de Política Migratoria, Consejo Nacional de Población, Secretaría de Relaciones Exteriores, Secretaría del Trabajo y Previsión Social, Consejo Nacional para Prevenir la Discriminación, Secretaría de Bienestar. Disponible en: https:/www.colef.mx/emif/datasets/informes/sur/2018/ Emif\%20Sur\%20Informe\%20Anual\%202018.pdf (Consultado el 23 de junio de 2020).

Gobierno de México (2020). Boletines estadísticos (2014-2020) [en línea]. Disponible en: http://www.politicamigratoria.gob.mx/es/PoliticaMigratoria/Boletines Estadisticos (Consultado el 19 de diciembre de 2020).

EntreDiversidades. Revista de Ciencias Sociales y Humanidades, Vol. 8, Núm. 2 (17), julio-diciembre 2021. Páginas: 145-166 ISSN-e: 2007-7610. https://doi.org/10.31644/ED.V8.N2.2021.A07 
Gómez Navarro, Lina Yismeray (2020). "El desasosiego llamado México. Personas no nacidas en México, en tránsito dentro de México, hacia Estados Unidos y otros países”. Migraciones en México: fronteras, omisiones y transgresiones. México: Redodem, pp. 19-37.

Goldring, Luin y Landolt, Patricia (2013). “The Conditionality of Legal Status and Rights: Conceptualizing Precarious Non-Citizenship in Canada”, en Goldring, Luin y Landolt, Patricia (eds.). Producing and Negotiating Non-Citizenship: Precarious Legal Status in Canada. Canada: University of Toronto Press, pp. 3-27.

Heyman, Josiah y Slack, Jeremy (2018). Blockading Asylum Seekers at Ports of Entry at the USMexico Border Puts Them at Increased Risk of Exploitation, Violence, and Death [en línea]. Center for Migration Studies, cmsny.org. doi: https://doi.org/10.14240/cmsesy062518 (Consultado el 23 de junio de 2020).

Joseph, Anna, Margarita Juárez Aparicio y Allena Martin (2019). Mexican Tarjetas de Vistitante por Razones Humanitarias and Firm Resettlement: A practice Advisory for Advocates. Ciudad de México, México: Instituto para las Mujeres en la Migración, A.C. Disponible en: https://imumi.org/attachments/2019/Mexican\%20Tarjetas\%20de\%20Visitante\%20 por\%20Razones\%20Humanitarias\%20and\%20Firm\%20Resettlement \%20-\%20A\%20 Practice\%20Advisory\%20for\%20Advocates.pdf (Consultado el 14 de diciembre de 2020).

Kerwin, Helen (2018). "The Mexican Asylum System in Regional Context". Maryland Journal of International Law [en línea], 33 (1), pp. 290-312. Disponible en: https://digitalcommons. law.umaryland.edu/cgi/viewcontent.cgi? article=1680\&context=mjil (Consultado el 14 de diciembre de 2020).

Ley de Migración (LM) (2017). Ley de Migración 2011 y reformas posteriores, Diario Oficial de la Federación, México. Disponible en: http://www.diputados.gob.mx/LeyesBiblio/ref/ lmigra/LMigra ref06 09nov17.pdf (Consultado: 23 de junio de 2020).

Lineamientos para trámites y procedimientos migratorios (LTPM) (8 de noviembre de 2012). Lineamientos para trámites y procedimientos migratorios. Disponible en: http:// www.inm.gob.mx/static/marco juridico/pdf/acuerdos/2012/Lineamientos tramites procedimientos migratorios.pdf (Consultado el 19 de noviembre de 2020).

Martínez, Carlos (2019). "El nuevo gobierno mexicano abrió las puertas a la caravana migrante". El Faro [en línea]. Disponible en: https:/elfaro.net/es/201901/centroamerica/22900/Elnuevo-gobierno-mexicano-abri\%C3\%B3-las-puertas-a-la-caravana-migrante.htm (Consultado el 6 de diciembre de 2020).

Martínez, Fabiola (2019) "Se suspendió la entrega de permisos a cubanos y haitianos; los oficios eran utilizados para el tráfico humano”. La Jornada [en línea]. Disponible en: https://www. jornada.com.mx/2019/04/19/politica/004n2pol (Consultado el 6 de diciembre de 2020).

Menjívar, Cecilia (2006). "Liminal Legality: Salvadoran and Guatemalan Immigrants' Lives in the United States". American Journal of Sociology, 111 (4), pp. 999-1037. También disponible en: https://doi.org/10.1086/499509

EntreDiversidades. Revista de Ciencias Sociales y Humanidades, Vol. 8, Núm. 2 (17), julio-diciembre 2021. Páginas: 145-166 ISSN-e: 2007-7610. https://doi.org/10.31644/ED.V8.N2.2021.A07 
Méroné, Schwarz Coulange y Castillo, Manuel Ángel (2018). "La reciente ola de haitianos a México: ¿Tránsito prolongado o formación de un nuevo destino migratorio?”. Prontuario sobre poblaciones migrantes en condiciones de vulnerabilidad. México: Unidad de Política Migratoria, Subsecretaría de Población, Migración y Asuntos Religiosos, Secretaría de Gobernación, pp. 56-60. También disponible en: https://www.researchgate.net/ publication/330657771 LA RECIENTE OLA DE HAITIANOS A MEXICO TRANSITO PROLONGADO O FORMACION DE UN NUEVO DESTINO MIGRATORIO

Migration Policy Institute (2019). Una nueva politica migratoria para una nueva era: Una conversación con la Secretaria de Gobernación Olga Sánchez Cordero [video]. Disponible en: $\quad$ https://www.migrationpolicy.org/events/una-conversacion-con-la-secretariagobernacion-Mexico (Consultado el 23 de junio de 2020).

Observatorio de Protección Internacional (2019). Situación de solicitantes de asilo de origen venezolano. Universidad Iberoamericana. Disponible en: https://asiloenmexico.ibero.mx/ informes/situacion-de-solicitantes-de-asilo-de-origen-venezolano/ (Consultado el 23 de junio de 2020).

Oxman-Martinez, Jacqueline, et al. (2005). "Intersection of Canadian Policy Parameters Affecting Women with Precarious Immigration Status: A Baseline for Understanding Barriers to Health”. Journal of Immigrant and Minority Health [en línea], 7 (4), pp. 247258. doi: https://link.springer.com/article/10.1007/s10903-005-5122-2 (Consultado el 20 de diciembre de 2020).

París Pombo, María Dolores (2018). "Factores y condiciones del flujo migratorio de solicitantes de asilo o refugio en Tijuana”, en París Pombo, María Dolores (coord.). Migrantes haitianos y centroamericanos en Tijuana, Baja California, 2016-2017. Politicas gubernamentales y acciones de la Sociedad civil. México: Comisión Nacional de Derechos Humanos México, El Colegio de la Frontera Norte, pp. 20-33. Disponible en: https://www.cndh.org.mx/ sites/all/doc/Informes/Especiales/Informe-Migrantes-2016-2017.pdf (Consultado el 23 de junio de 2020).

París Pombo, María Dolores y Montes, Verónica (2020). "Visibilidad como estrategia de movilidad: el éxodo centroamericano". EntreDiversidades [en línea], 7 (1), pp. 9-37. doi: https://doi.org/10.31644/ED.V7.N1.2020.A01 (Consultado el 23 de junio de 2020).

Pradilla, Alberto (2019a). Caravana. Cómo el éxodo centroamericano salió de la clandestinidad. España: Penguin Random House Grupo Editorial.

Pradilla, Alberto (2019b). "Nueva caravana migrante: todo cambia salvo las razones para huir". Plaza Pública [en línea]. Disponible en: https://www.plazapublica.com.gt/content/ nueva-caravana-migrante-todo-cambia-salvo-las-razones-para-huir (Consultado el 23 de junio de 2020).

Pradilla, Alberto (2020a). "No habrá salvoconductos ni visas de tránsito, advierte Segob ante nueva caravana migrante". Animal Politico [en línea]. Disponible en: https://www.animalpolitico.com/2020/01/caravana-migrante-sanchez-corderooperativos-especiales/ (Consultado el 23 de junio de 2020).

EntreDiversidades. Revista de Ciencias Sociales y Humanidades, Vol. 8, Núm. 2 (17), julio-diciembre 2021. Páginas: 145-166 ISSN-e: 2007-7610. https://doi.org/10.31644/ED.V8.N2.2021.A07 
Pradilla, Alberto (2020b). “Venimos por necesidad': las historias de migrantes que hacen todo para llegar a EU”. Animal Politico [en línea]. Disponible en: https://www.animalpolitico. com/2020/01/migrantes-llegar-eu-deportados-mexico/ (Consultado el 23 de junio de 2020).

Ramírez, Andrés (2019). [Twitter] 13 de diciembre. Disponible en: https://twitter.com/ AndresRSilva/status/1212033738063912960?s=20 (Consultado el 1 de enero de 2021).

Ramírez, Andrés (2020a). [Twitter] 1 de diciembre. Disponible en: https://twitter.com/ AndresRSilva/status/1333965154111934464?s=20 (Consultado el 1 de enero de 2021).

Ramírez, Andrés (2020b). [Twitter] 2 de diciembre. Disponible en: https://twitter.com/ AndresRSilva/status/1334123471685754891?s=20 (Consultado el 1 de enero de 2021).

Reglamento de la Ley de Migración (RLM) (2014). Reglamento de la Ley de Migración y reformas posteriores, Diario Oficial, México, 23 de mayo de 2014. Disponible en: http://www.diputados.gob.mx/LeyesBiblio/regley/Reg_LMigra.pdf (Consultado el 19 de diciembre de 2020).

Robert Strauss Center, et al. (2018). Asylum Processing and Waitlists at the U.S.-Mexico Border. December 2018 [en línea]. United States of America: European University Institute, Robert Strauss Center, Center for U.S.-Mexican Studies. Disponible en: https://www.strausscenter.org/publications/asylum-processing-and-waitlists-at-the-u-smexico-border/ (Consultado el 23 de junio de 2020).

Rodríguez Chávez, Ernesto (2016). "Nuevas tendencias en la migración centroamericana en tránsito irregular por México”. Central America North America Migration Dialogue Policy Brief Series [en línea] PB14. México: Centro de Investigaciones y Estudios Superiores en Antropología Social. Disponible en: http://www.canamid.org/publication?id=PB014 (Consultado el 23 de junio de 2020).

Secretaría de Relaciones Exteriores y Secretaría de Gobernación (SRE y Segob) (2018). Medidas del gobierno de México ante la eventual llegada a la frontera sur de la caravana de migrantes hondureños [en línea]. Disponible en: https://embamex.sre.gob.mx/guatemala/index.php/ prensa/1024-medidas-del-gobierno-de-mexico-ante-la-eventual-llegada-a-la-fronterasurde-la-caravana-de-migrantes-hondurenos (Consultado el 23 de junio de 2020).

Semple, Kirk (2019). "Las políticas de AMLO han contribuido al auge de la migración hacia Estados Unidos". The New York Times [en línea]. Disponible en: https://www.nytimes. com/es/2019/04/02/amlo-migracion-trump/ (Consultado el 23 de junio de 2020).

Thayer Correa, Luis Eduardo, Fernanda Stang y Cristóbal Abarca (2016). "Estatus legal precario y condicionalidad en el acceso a derechos: Una aproximación a la regulación migratoria de Argentina y Canadá". Si Somos Americanos. Revista de Estudios Transfronterizos [en línea], 16 (2), pp 11-43. Disponible en: https://scielo.conicyt.cl/scielo.php?script=sci abstract\&pid=S0719-09482016000200001\&lng=es\&nrm=iso (Consultado el 1 de enero de 2021).

EntreDiversidades. Revista de Ciencias Sociales y Humanidades, Vol. 8, Núm. 2 (17), julio-diciembre 2021. Páginas: 145-166 ISSN-e: 2007-7610. https://doi.org/10.31644/ED.V8.N2.2021.A07 
Torre Cantalapiedra, Eduardo (2020). "Destino y asentamiento en México de los migrantes y refugiados centroamericanos". Revista Trace - Procesos Mexicanos y Centroamericanos [en línea], Núm. 77. doi: http://dx.doi.org/10.22134/trace.77.2020.726 (Consultado el 23 de junio de 2020).

Torre Cantalapiedra, Eduardo y Mariscal Nava, Dulce María (2020). "Batallando con fronteras: estrategias migratorias en tránsito de participantes en caravanas de migrantes". Estudios Fronterizos [en línea], Vol. 21. doi: https://doi.org/10.21670/ref.2005047 (Consultado el 23 de junio de 2020).

UniMexicali (2018). "Haitianos con dificultades para renovar su visa en Mexicali". Uniradio Informa [en línea]. Disponible en: https://www.uniradioinforma.com/noticias/ mexicali/538877/haitianos-con-dificultades-para-renovar-su-visa-en-mexicali.html (Consultado el 23 de junio de 2020).

Yee Quintero, José Carlos (2017). "Caracterizando los solicitantes de asilo en Casa del Migrante”, en Vidas en vilo. Historias y testimonios de migrantes internacionales. Tijuana, México: Casa del Migrante en Tijuana, A.C., pp. 53-83.

EntreDiversidades. Revista de Ciencias Sociales y Humanidades, Vol. 8, Núm. 2 (17), julio-diciembre 2021. Páginas: 145-166 ISSN-e: 2007-7610. https://doi.org/10.31644/ED.V8.N2.2021.A07 